\title{
OPTIMASI PARAMETER PROSES PENJEMURAN GABAH DENGAN MENGGUNAKAN METODE TAGUCHI
}

\author{
Kemas Muhammat Abdul Fatah ${ }^{1 *}$, Wisnaningsih ${ }^{2}$ \\ ${ }^{(1,2)}$ Prodi Teknik Mesin Universitas Sang Bumi Ruwa Jurai \\ kmsmafattah@email.com
}

\begin{abstract}
Abstrak.
Proses penjemuran gabah bertujuan untuk mengeringkan gabah di bawah sinar matahari secara langsung tanpa perantara (terbuka). Pengeringan dengan cara ini menjadi pilihan umumnya petani karena menguntungkan secara ekonomi malaupun memiliki kekurangan terkait dengan penyusutan karena kehilangan selama proses penjemuran. Pada cuaca terik, proses pengeringan padi sampai pada tingkat GKP diperlukan waktu $2-3$ hari. Penelitian ini ditujukan untuk mengoptimasi proses penjemuran dengan mempertimbangkan faktor-faktor yang mempengaruhi yaitu, media alas hamparan gabah (media jemur), tebal hamparan gabah dan frekuensi pembalikan. Penelitian dilakukan melalui sejumlah eksperimen dengan menggunakan desain eksperimen metode Taguchi $\mathrm{L}_{9}\left(3^{3}\right)$. Dari hasil perhitungan efek mean dan SNR diketahui bahwa frekuensi pembalikan menempati urutan ke-1, diikuti media jemur dan tebal gabah secara berturut-turut, pengaruhnya terhadap penyusutan kadar air, dan untuk mendapatkan proses penjemuran yang optimal, frekuensi pembalikan sebanyak 4 kali, kombinasi terpal talang dan terpal plastik sebagai media jemur, dan tebal gabah adalah $2 \mathrm{~cm}$. Analisis varians mengungkapkan bahwa ke-3 faktor tidak siginifikan pengaruhnya terhadap penyusutan kadar air dengan kontribusi sebesar $77,17 \%$.
\end{abstract}

Kata kunci: Pengeringan, Penjemuran, Metode Taguchi

\begin{abstract}
.
Open sun drying of grain aimed to dry grain under solar radiation directly without any cover and this method is common because its benefit economically, even this method has drawback related to volume lost during drying process. It took $2-3$ days in drying duration when the day is hot. This study aimed to optimize drying process with considering some factors, namely drying media, grain layer thickness, and reversal frequency. Research was conducted for some experiment following Taguchi Method $L_{9}\left(3^{3}\right)$. SNR calculation found the reversal frequently to become the first rank, drying media and grain layer thickness, respectively in influencing moisture lost. To find optimal drying process required to set drying media is plastic sheet combined with gutter sheet, 4 times of reversal frequently and $2 \mathrm{~cm}$ of grain layer thickness. ANOVA revealed the three of factors are insignificant in influencing moisture lost with contributing $77,17 \%$.
\end{abstract}

Keywords: drying, open sun drying, Taguchi Method

\section{PENDAHULUAN}

Pada tahun 2017, tanaman pangan (termasuk padi sawah) merupakan golongan yang memberikan kontribusi terbesar dalam Subketegori pertanian, yaitu sebesar 36,62\% dari 30,40\% PDRB provinsi Lampung (BPS, 2018). Dengan demikian, usaha-usaha yang ditujukan untuk memperbaiki hal-hal yang terkait dengan tanaman pangan, khususnya padi sawah, secara langsung dan tidak langsung akan berdampak terhadap perbaikan perekonomian masyarakat Lampung, dan salah satu hal yang dapat dilakukan adalah mengoptimalkan proses pengeringan gabah. Keterlambatan pengeringan atau pengeringan yang tidak baik akan menurunkan bobot dan mutu gabah. Kadar air yang tinggi memungkinkan serangga berkembang dengan baik, IRRI merekomendasikan bahwa pengeringan harus sudah dilakukan paling lambat 12 jam setelah padi di panen (Swastika 2012). 
Proses pengeringan pada prinsipnya adalah perpindahan panas dan perpindahan massa, keduanya terjadi secara bersamaan (simultan). Pertama panas harus di transfer dari medium pemanas ke bahan. Selanjutnya setelah terjadi penguapan air, uap air yang terbentuk harus dipindahkan melalui struktur bahan ke medium sekitarnya. Proses ini akan menyangkut aliran fluida di mana cairan harus ditransfer melalui struktur bahan selama proses pengeringan berlangsung. Jadi panas harus di sediakan untuk menguapkan air dan air harus mendifusi melalui berbagai macam tahanan agar supaya dapat lepas dari bahan dan berbentuk uap air yang bebas, dibutuhkan panas yang lebih tinggi untuk percepatan proses penguapan (Mazandarani et al. 2017). Namun demikian, untuk proses pengeringan gabah, dengan temperatur tinggi sehingga terjadi penyusutan kadar air dari $19 \%$ menjadi $14 \%$ dalam waktu singkat, akan berakibat beras pecah pada proses penggilingan (Chakraborty et al. 2016).

Energi panas yang dibutuhkan di dalam proses pengeringan dapat bersumber dari bahan bakar fossil dan energi matahari. Dalam konteks keterbatasan energy fossil, pemanfaatan bahan bakar fossil dewasa ini harus mulai dikurangi, sementara pemanfaatan energi matahari sebagai sumber energi yang dapat diperbaharui harus menjadi pilihan untuk proses pengeringan produk agro (Lamidi et al. 2019).

Energi panas matahari sebagai sumber panas dapat dimanfaatkan dengan 2 metode, yaitu dengan metode panas matahari langsung (open sun drying) atau penjemuran dan metode ke-2 dengan alat pengering (solar driyer), dimana ide pengembangan solar driyer muncul untuk mendapatkan mutu produk yang tidak dapat diperoleh dengan penjemuran (M. Kumar, Sansaniwal, and Khatak 2016). Namun, penjemuran tetap menjadi metode pengeringan untuk produk agro yang umum digunakan di banyak tempat di dunia, ketika radiasi matahari dirasakan masih nyaman (Toğrul et al, 2007), salah satunya bagi petani di Lampung.

Penjemuran gabah yang dilakukan oleh petani adalah untuk menurunkan kadar air sampai tingkat dimana gabah aman untuk disimpan atau Gabah Kering Simpan (GKS) atau pada tingkat Gabah Kering Giling (GKG). Dalam proses pengeringan, kadar air gabah hasil proses perontokan sekitar 30\% diturunkan menjadi 18 - 25\% untuk mencapai Gabah Kering Panen (GKP), dan diturunkan menjadi 14\% - 18\% untuk mencapai Gabah Kering Simpan (GKS) dan menjadi maksimal $14 \%$ untuk mencapai Gabah Kering Giling (GKG). Untuk mencapai kekeringan gabah pada pada tingkat GKP, GPS atau GKG sangat tergantung pada parameter proses pengeringan misalnya energi panas, kadar air, temperatur, tingkat aliran udara pengering (Kumar et al., 2016).

Penjemuran gabah dengan cara dihamparkan dengan ketebalan tertentu dapat dipandang sebagai pengeringan lapisan tipis dimana bidang pengeringan lebih besar dan ketebalan bahan dikurangi sehingga pengeringan berlangsung serentak dan merata (Sudirman et. al., 2018), terjadi karena semua bahan yang terdapat dalam lapisan menerima langsung aliran udara dengan suhu dan kelembaban relatif yang mendekati konstan, dimana pada saat itu kadar air dan suhu bahan keduanya seragam (Santoso et al., 2018).

Dalam penelitian ini penulis melakukan analisa terkait pengaruh variasi media jemur, ketebalan gabah dan frekuensi pembalikan terhadap penyusutan kadar air. Desain eksperimen dan hasil eksperimen berupa penyusutan kadar air ditentukan dan dianalisa menggunakan metode Taguchi untuk mendapatkan variasi faktor yang optimal. Penyusutan kadar air dipilih sebagai respon pada penelitian ini karena kadar air merupakan salah satu item dari mutu gabah (Chakraborty et al. 2016).

\section{METODE PENELITIAN}

Penelitian ini dilaksanakan di laboratorium program studi Teknik Mesin Universitas Sang Bumi Ruwa yang beralamat di Jl. Imam Bonjol, No. 468, Langkapura, Bandar Lampung. Pelaksanaan Penelitian Pengambangan dilakukan pada Bulan Oktober 2020.

Desain eksperimen yang digunakan pada penelitian ini menggunakan metode Taguchi 
orthogonal array $\mathrm{L}_{9}\left(3^{3}\right)$ yang mempunyai kombinasi 3 faktor dan setiap factor memiliki 3 level seperti yang ditunjukkan pada Tabel 1 berikut.

Tabel 1. Faktor Kontrol dan Level

\begin{tabular}{|c|c|c|c|}
\hline Faktor & Level & & \\
\hline Media Jemur (A) & $\begin{array}{l}\text { Terpal talang } \\
\text { (X) }\end{array}$ & $\begin{array}{l}\text { Terpal plastik } \\
\text { (Y) }\end{array}$ & $\begin{array}{l}\text { Terpal talang }+ \\
\text { terpal plastik }(\mathrm{Z})\end{array}$ \\
\hline Tebal hamparan gabah (B) & $2 \mathrm{~cm}$ & $3 \mathrm{~cm}$ & $4 \mathrm{~cm}$ \\
\hline Frekuensi pembalikan (C) & 4 kali & 6 kali & 8 kali \\
\hline
\end{tabular}

Pemilihan media jemur sebagai faktor dalam penelitian ini karena panas matahari yang diserap oleh media jemur akan menjadi sumber panas untuk membantu penguapan secara konveksi dan secara konduksi, perbedaan media jemur tentu akan memberikan pengaruh yang berbeda terhadap penguapan. Ketebalan gabah sebagai faktor dalam penelitian ini karena ketebalan dalam proses pengeringan adalah parameter penting (Tun et al. 2020), ketebalan yang berbeda tentu akan berbeda pengaruhnya terhadap penguapan. Frekuensi pembalikan sebagai faktor dalam penelitian ini karena tujuan pembalikan adalah untuk mengurangi tahanan selama proses difusi air sehingga berbentuk uap air yang bebas, frekuensi pembalikan yang berbeda tentu akan berbeda pengaruhnya terhadap penguapan.

Alat yang digunakan pada penelitian ini yaitu terdiri dari gunting potong aluminium, penggaris, double tape untuk membuat mal ketebalan jemur, rubber scrapper untuk meratakan ketebalan jemur, timbangan digital dan pengukur kadar air.

Bahan yang digunakan pada penelitan ini yaitu plate aluminium untuk mal ketebalan penjemuran gabah, terpal talang, terpal plastik sebagai media jemur dan gabah sebagai objek penelitian.

\section{Pelaksanaan eksperimen}

Prosedur di dalam pelaksanaan eksperimen adalah :

1. Siapkan beberapa mal ketebalan penjemuran gabah, masing-masing adalah tebal $2 \mathrm{~cm}$, $3 \mathrm{~cm}$ dan $4 \mathrm{~cm}$, seperti yang tampak pada Gambar 1 di bawah ini.

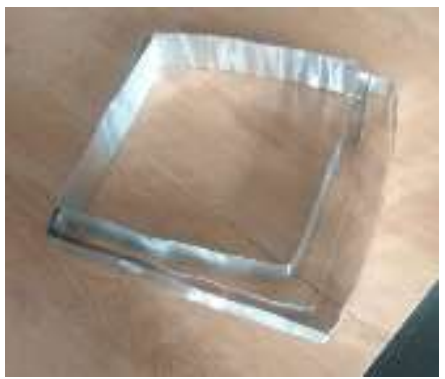

Gambar 1. Mal Ketebalan Gabah

2. Persiapkan lembar kontrol eksperimen untuk memudahkan identifikasi dan pencatatan, mengikuti urutan sesuai standar OA L $9\left(3^{3}\right)$

3. Timbang gabah yang akan dijemur sebanyak 8 wadah dengan volume yang sama, catat berat hasil timbang.

4. Persiapkan media jemur di atas lantai beton, masing-masing adalah media jemur dengan terpal talang $(\mathrm{X})$, media jemur dengan terpal plastik $(\mathrm{Y})$, dan media jemur dengan terpal plastik ditumpuk di atas terpal talang $(\mathrm{Z})$. 
5. Curahkan masing-masing gabah di atas media jemur dengan posisi yang berbeda, seperti yang tampak pada Gambar 2 di bawah ini.

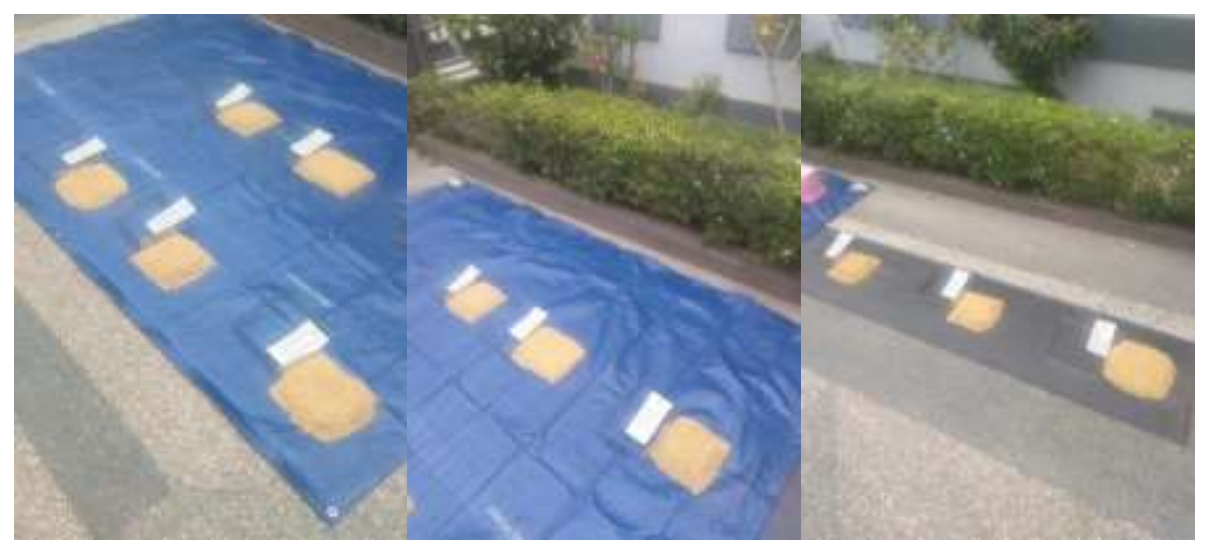

Gambar 2. Penjemuran gabah dengan media jemur yang berbeda

6. Atur ketebalan penjemuran gabah dengan menggunakan mal yang sudah dipersiapkan dan diratakan, seperti yang tampak pada Gambar 3.

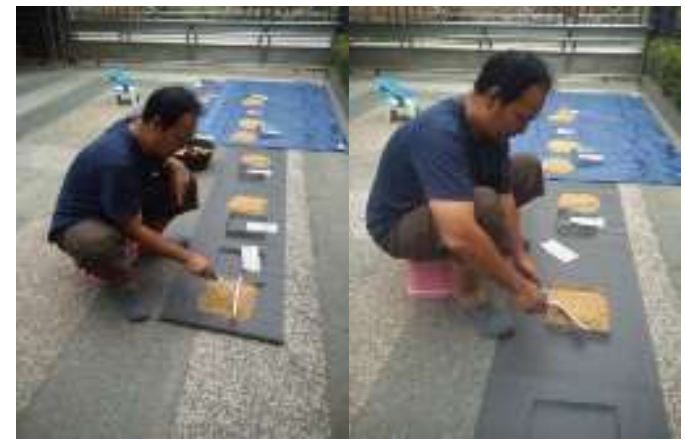

Gambar 3. Mengatur ketebalan jemur gabah

7. Lakukan pembalikan gabah sesuai waktu yang telah ditentukan, lalu atur kembali ketebalan jemur seperti pada langkah 6 .

8. Ukur kadar air gabah pada setiap periode pembalikan untuk mengetahui perubahan kadar air, seperti yang tampak pada Gambar 4.

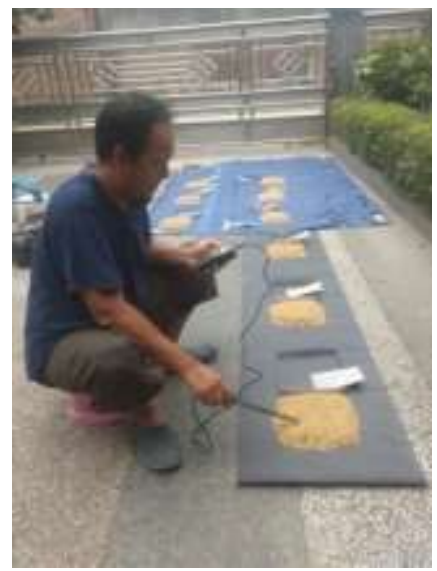

\section{Teknik pengumpulan data}

Gambar 4. Pengukuran kadar air

Teknik pengumpulan data adalah dengan menimbang kembali masing-masing tumpukan gabah setalah melalui proses pengeringan selama 4 jam, lalu hitung penyusutan kadar air, yaitu 
selisih berat gabah sebelum dijemur dan setelah dijemur.

\section{Analisis data}

Data hasil penelitian selanjutnya dianalisis dengan perhitungan untuk mendapatkan nilai Signal to Ratio (SNR), dimana nilai SNR adalah sebagai ukuran tingkat sensitivitas dari kualitas masing-masing faktor yang dikendalikan terhadap pengaruh faktor dari luar yang tidak dikendalikan. Data hasil eksperimen juga dianalisa dengan ANOVA, untuk mengetahui pengaruh masing-masing faktor terhadap respon (N. Kumar, Kumar, and Khurmi 2016) artikel sebelumnya dengan menggunakan satu hipotesis yaitu hipotesis dua arah (two tail) yang artinya hipotesis bertujuan untuk mengetahui ada tidaknya perbedaan rata-rata dalam eksperimen. Penelitian ini menetapkan nilai $\alpha$ adalah 0,05 .

\section{HASIL DAN PEMBAHASAN}

\section{Hasil Penelitian}

Setelah dilakukan penimbangan terhadap gabah hasil proses pengeringan pada masingmasing eksperimen, diperoleh data seperti yang terlihat pada Tabel 2 berikut ini.

Tabel 2. Data gabah hasil eksperimen

\begin{tabular}{llll}
\hline \multirow{2}{*}{ Ekeperimen } & Berat (gram) & & \\
\cline { 2 - 4 } & Sebelum dijemur & Setelah dijemur & Selisih \\
\hline 1 & 625 & 592 & 33 \\
2 & 623 & 588 & 35 \\
3 & 645 & 624 & 21 \\
4 & 625 & 594 & 31 \\
5 & 630 & 608 & 22 \\
6 & 626 & 589 & 37 \\
7 & 625 & 591 & 34 \\
8 & 632 & 596 & 36 \\
9 & 633 & 598 & 35 \\
\hline
\end{tabular}

Berdasarkan data-data yang tercantum pada Tabel 2 diatas, selanjutnya akan dihitung nilai SNR (berdasarkan kategori smaller is better), dengan menggunakan Software statistika Minitab 19, diperoleh hasil sebagai berikut.

Tabel 3. Nilai SNR masing-masing eksperimen

\begin{tabular}{lll}
\hline Eksperimen & Penyusutan kadar air & SNR \\
\hline 1 & 33 & $-30,3703$ \\
2 & 35 & $-30,8814$ \\
3 & 21 & $-26,4444$ \\
4 & 31 & $-29,8272$ \\
5 & 22 & $-26,8485$ \\
6 & 37 & $-31,3640$ \\
7 & 34 & $-30,6296$ \\
8 & 36 & $-31,1261$ \\
9 & 35 & $-30,8814$
\end{tabular}

Berdasarkan hasil perhitungan SNR diatas, akan dianalisa berdasarkan 2 cara, yaitu dengan perhitungan efek dari mean dan perhitungan efek dari SNR. Dengan menggunakan Software statistika Minitab 19 untuk mengetahui efek dari mean, diperoleh hasil sebagai berikut: 
Tabel 4. Efek dari mean

\begin{tabular}{llll}
\hline Level & Media Jemur & Tebal Gabah & Frekuensi Pembalikan \\
\hline 1 & 29,67 & 32,67 & 35,33 \\
2 & 30,00 & 31,00 & 33,67 \\
3 & 35,00 & 31,00 & 25,67 \\
Delta & 5,33 & 1,67 & 9,67 \\
Rank & 2 & 3 & 1 \\
\hline
\end{tabular}

Dari angka-angka pada Tabel 4, tampak bahwa faktor yang memiliki pengaruh terbesar hingga terkecil terhadap penyusutan kadar air pada proses pengeringan gabah adalah faktor frekuensi pembalikan dengan nilai 9,67 berada pada urutan ke-1, faktor media jemur dengan nilai 5,33 berata pada urutan ke-2, dan faktor tebal gabah dengan nilai 1,67 berada pada urutan ke-3.

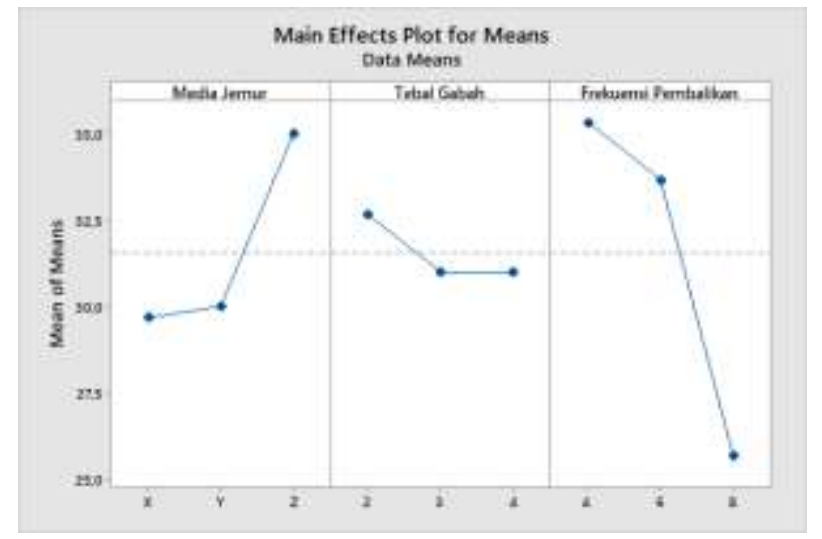

Gambar 1. Efek utama dari mean

Sementara itu, berdasarkan Gambar 5 dapat digunakan untuk menentukan nilai optimum pada setiap faktor adalah dengan cara memilih nilai terbesar pada masing-masing faktor, sehingga untuk media jemur, media jemur terpal plastik yang ditumpuk pada terpal talang adalah media jemur yang paling optimal. Untuk ketebalan, dengan tebal jemur $2 \mathrm{~cm}$ adalah ketebalan optimum. Untuk frekuensi pembalikan, frekuensi pembalikan sebanyak 4 kali selama 4 jam penjemuran atau setiap 1 jam, adalah frekuensi pembalikan optimal.

Dengan menggunakan Software statistika Minitab 19 untuk mengetahui efek dari SNR, diperoleh hasil sebagai berikut.

Tabel 5. Efek dari SNR

\begin{tabular}{llll}
\hline Level & Media Jemur & Tebal Gabah & Frekuensi Pembalikan \\
\hline 1 & $-29,23$ & $-30,28$ & $-30,95$ \\
2 & $-29,35$ & $-29,62$ & $-30,53$ \\
3 & $-30,88$ & $-29,56$ & $-27,97$ \\
Delta & 1,65 & 0,71 & 2,98 \\
Rank & 2 & 3 & 1 \\
\hline
\end{tabular}

Dari angka-angka pada Tabel 5, dari efek nilai SNR tampak bahwa faktor yang memiliki pengaruh terbesar hingga terkecil terhadap penyusutan kadar air pada proses pengeringan gabah adalah faktor frekuensi pembalikan dengan nilai 2,98 berada pada urutan ke-1, faktor media jemur dengan nilai 1,65 berada pada urutan ke-2, dan faktor tebal gabah dengan nilai 0,71 berada pada 
urutan ke-3.

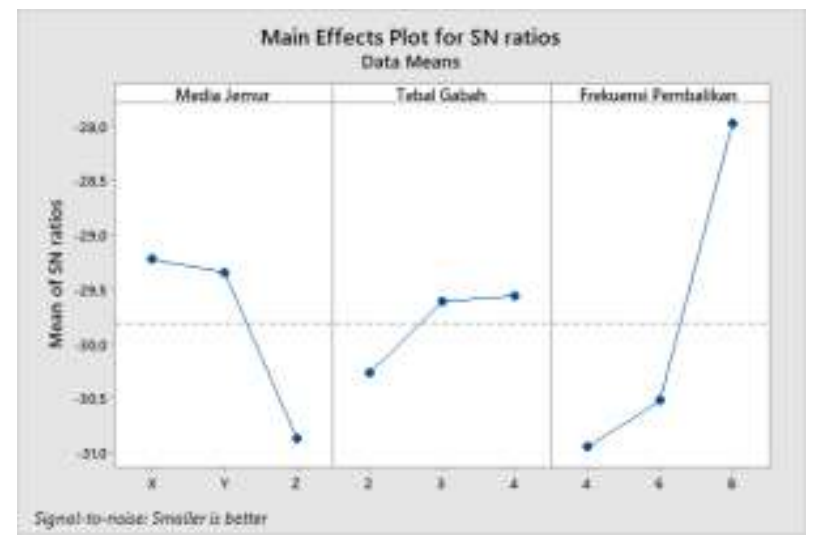

Gambar 2. Efek utama dari SNR

Sementara itu, berdasarkan Gambar 2 dapat digunakan untuk menentukan nilai optimum pada setiap faktor adalah dengan cara memilih nilai terkecil pada masing-masing faktor, sehingga untuk media jemur, media jemur terpal plastik yang ditumpuk pada terpal talang adalah media jemur yang paling optimal. Untuk ketebalan, dengan tebal jemur $2 \mathrm{~cm}$ adalah ketebalan optimum. Untuk frekuensi pembalikan, frekuensi pembalikan sebanyak 4 kali selama 4 jam penjemuran atau setiap 1 jam, adalah frekuensi pembalikan optimal.

\section{Pembahasan}

Dari perhitungan efek dari mean dan efek dari SNR, diketahui bahwa faktor frekuensi pembalikan adalah menempati urutan ke-1, diikuti secara berturut-turut faktor media jemur dan tebal gabah. Sementara itu, untuk mengetahui seberapa besar pengaruh masing-masing faktor terhadap penyusutan kadar air dan juga untuk mengetahui pengaruh perubahan level pada setiap faktor, perlu dilakukan analysis of variance (ANOVA), dimana analisis varian adalah salah satu teknik dalam menganalisa dan menguraikan seluruh variasi atas bagian-bagian yang diteliti dengan tujuan untuk mengidentifikasi pengaruh faktor agar dapat ditentukan nilai parameter yang tepat di dalam proses pengeringan. Dengan menggunakan Software statistika Minitab 19 untuk ANOVA, diperoleh hasil sebagai berikut.

Tabel 6. Hasil analisis Anova

\begin{tabular}{llllllll}
\hline Source & DF Seq SS & Contribution Adj SS & Adj MS & F-Value & P-Value \\
\hline Media Jemur & 2 & 53,556 & $18,84 \%$ & 53,556 & 26,778 & 0,83 & 0,548 \\
Tebal Gabah & 2 & 5,556 & $1,95 \%$ & 5,556 & 2,778 & 0,09 & 0,921 \\
Frekuensi & 2 & 160,222 & $56,37 \%$ & 160,222 & 80,111 & 2,47 & 0,288 \\
Pembalikan & & & & & & & \\
Error & 2 & 64,889 & $22,83 \%$ & 64,889 & 32,444 & & \\
Total & 8 & 284,222 & $100,00 \%$ & & & & \\
\hline
\end{tabular}

Dari Tabel 6 dapat dilakukan pengujian hipotesa dari nilai F-hitung dibandingkan dengan nilai F-tabel, sehingga dapat diambil keputusan apakah nilai dari F-hitung setiap faktor ditolak atau diterima.

\section{Hipotesis untuk faktor A (media jemur)}

$\mathrm{H}_{0}$ : Tidak ada pengaruh perlakuan faktor A terhadap penyusutan kadar air

$\mathrm{H}_{1}$ : Ada pengaruh perlakuan faktor A terhadap penyusutan kadar air 
Level signifikan (a) : 0,05

$\mathrm{F}_{\text {tabel }(0,05,2,2)}=19$

Statistik uji:

$F_{\text {hitung }}=0,83$

Sehingga, $F_{\text {hitung }}<\mathrm{F}_{\text {tabel }}$

$0,83<19$

Maka $\mathrm{H}_{0}$ diterima dimana tidak ada pengaruh perlakuan faktor A yang signifikan terhadap penyusutan kadar air. Sementara itu, dengan nilai $\mathrm{p}$ value sebesar 0,548 yang lebih besar dari nilai $\alpha$, dapat disimpulkan bahwa tidak ada perbedaan yang nyata besarnya penyusutan kadar air pada penggunaan media jemur yang berbeda, baik menggunakan terpal talang (X), terpal plastik (Y), atau kombinasi terpal talang dan terpal plastik (Z).

\section{Hipotesis untuk faktor B (tebal gabah)}

$\mathrm{H}_{0}$ : Tidak ada pengaruh perlakuan faktor B terhadap penyusutan kadar air

$\mathrm{H}_{1}$ : Ada pengaruh perlakuan faktor $\mathrm{B}$ terhadap penyusutan kadar air

Level signifikan (a) : 0,05

$\mathrm{F}_{\text {tabel }(0,05,2,2)}=19$

Statistik uji:

$F_{\text {hitung }}=0,09$

Sehingga, $\mathrm{F}_{\text {hitung }}<\mathrm{F}_{\text {tabel }}$

$2,47<19$

Maka $\mathrm{H}_{0}$ diterima dimana tidak ada pengaruh perlakuan faktor $\mathrm{C}$ yang signifikan terhadap penyusutan kadar air. Sementara itu, dengan nilai $p$ value sebesar 0,921 yang lebih besar dari nilai $\alpha$, dapat disimpulkan bahwa tidak ada perbedaan yang nyata besarnya penyusutan kadar air pada perubahan frekuensi pembalikan tebal gabah, baik gabah dijemur dengan ketebalan $2 \mathrm{~cm}, 3 \mathrm{~cm}$ atau $4 \mathrm{~cm}$.

\section{Hipotesis untuk faktor $\mathbf{C}$ (frekuensi pembalikan)}

$\mathrm{H}_{0}$ : Tidak ada pengaruh perlakuan faktor $\mathrm{C}$ terhadap penyusutan kadar air

$\mathrm{H}_{1}$ : Ada pengaruh perlakuan faktor $\mathrm{C}$ terhadap penyusutan kadar air

Level signifikan (a) : 0,05

$\mathrm{F}_{\text {tabel }}(0,05,2,2)=19$

Statistik uji:

$F_{\text {hitung }}=2,47$

Sehingga, $\mathrm{F}_{\text {hitung }}<\mathrm{F}_{\text {tabel }}$

$2,47<19$

Maka $\mathrm{H}_{0}$ diterima dimana tidak ada pengaruh perlakuan faktor $\mathrm{C}$ yang signifikan terhadap penyusutan kadar air. Sementara itu, dengan nilai $p$ value sebesar 0,288 yang lebih besar dari nilai $\alpha$, dapat disimpulkan bahwa tidak ada perbedaan yang nyata besarnya penyusutan kadar air pada perubahan tebal gabah, baik pembalikan gabah sebanyak 4 kali, 6 kali atau 8 kali.

\section{KESIMPULAN}

Berdasarkan hasil pengolahan data dan analisis yang dilakukan dengan metode Taguchi pada proses penjemuran gabah, dari perhitungan efek mean dan efek SNR, didapat bahwa frekuensi pembalikan memiliki pengaruh pada urutan ke-1 terhadap penyusutan kadar air dengan frekuensi pembalikan sebanyak 4 kali sebagai nilai yang optimal, media jemur menempati peringkat ke-2 dengan media jemur kombinasi terpal talang dan terpal plastik ( $Z$ ) adalah media jemur yang paling optimal, tebal gabah menempati peringkat ke-3 dengan ketebalan $2 \mathrm{~cm}$ adalah 
ketebalan yang optimal. Hasil uji hipotesis dengan analisis varians terhadap faktor-faktor yang mempengaruhi proses pengeringan, ketiga faktor tersebut tidak berpengaruh signifikan dan tidak ada perbedaan yang nyata atas perubahan pada masing-masing faktor. Secara keseluruhan ketiga faktor tersebut berpengaruh sebesar $77,17 \%$ terhadap penyusutan kadar air.

\section{UCAPAN TERIMAKASIH}

Terimakasih kepada Yayasan Pendidikan Saburai yang telah mendanai penelitian ini dan kepada LPPM Universitas Sang Bumi Ruwa Jurai yang telah menginisiasi program Grant Research 2020 sehingga menghasilkan penelitian ini.

\section{DAFTAR PUSTAKA}

BPS Provinsi Lampung. (2018). Produk Domestik Regional Bruto Provinsi Lampung Menurut Lapangan Usaha 2013-2017. Bandar Lampung: Badan Pusat Statistik Provinsi Lampung.

Chakraborty, Sourav, Mausumi Sarma, Jinku Bora, Shah Faisal, and M. K. Hazarika. (2016). "Generalization of Drying Kinetics during Thin Layer Drying of Paddy." Agricultural Engineering International: CIGR Journal 18(4):177-89.

Kumar, Mahesh, Sunil Kumar Sansaniwal, and Pankaj Khatak. (2016). "Progress in Solar Dryers for Drying Various Commodities." Renewable and Sustainable Energy Reviews 55:346-60.

Kumar, Nitish, Hemant Kumar, and Jagdeep Singh Khurmi. (2016). "Experimental Investigation of Process Parameters for Rapid Prototyping Technique (Selective Laser Sintering) to Enhance the Part Quality of Prototype by Taguchi Method." Procedia Technology 23:35260 .

Lamidi, Rasaq O., L. Jiang, Pankaj B. Pathare, Y. D. Wang, and A. P. Roskilly. (2019). Recent Advances in Sustainable Drying of Agricultural Produce: A Review. Vols. 233-234.

Mazandarani, Z., N. Aghajani, A. Daraei Garmakhany, M. J. Bani Ardalan, and M. Nouri. (2017). "Mathematical Modeling of Thin Layer Drying of Pomegranate (Punica Granatum L.) Arils: Various Drying Methods." Journal of Agricultural Science and Technology 19:1527-37.

Santoso, Dwi, Djunaedi Muhidong, and Mursalim. (2018). "Model Matematis Pengeringan Lapisan Tipis Biji Kopi Arabika (Coffeae Arabica) Dan Biji Kopi Robusta (Coffeae Cannephora)." Jurnal Teknologi Pertanian Andalas 22(1).

Sudirman, Nurafni Apriani, Andi Sukainah, and Subari Yanto. (2018). "Pengaruh Pengeringan Menggunakan Room Dryer Terhadap Kualitas Tepung Sagu.” Jurnal Pendidikan Teknologi Pertanian 4(2009):104.

Swastika, Dewa Ketut Sadra. (2012). "Teknologi Panen Dan Pascapanen Padi: Kendala Adopsi Dan Kebijakan Strategi Pengembangan.” Analisis Kebijakan Pertanian 10(4):331-46.

Toğrul, Inci Türk, and Hasan Toğrul. (2007). "Determination of Moisture Transport Parameters of Some Fruits under Open Sun Drying Conditions." International Journal of Green Energy 4(4):397-408. 
Seminar Nasional Penelitian dan Pengabdian kepada Masyarakat Universitas Sang Bumi Ruwa Jurai Tahun 2020

Tun, Maw Maw, Helena Raclavská, Dagmar Juchelková, Jana Růžičková, Michal Šafář, Kristína Štrbová, and Petros Gikas. (2020). "Spent Coffee Ground as Renewable Energy Source: Evaluation of the Drying Processes." Journal of Environmental Management 275(August). 